Policy analysis

\title{
Population status, connectivity, and conservation action for the endangered Baird's tapir
}

Cody J. Schank ${ }^{\mathrm{a}, \mathrm{b}, *}$, Michael V. Cove ${ }^{\mathrm{c}}$, Eugenio Y. Arima ${ }^{\mathrm{a}}$, Laroy S.E. Brandt ${ }^{\mathrm{d}}$, Esteban Brenes-Mora ${ }^{\mathrm{e}}$, Andrew Carver ${ }^{\mathrm{f}}$, Angelica Diaz-Pulido ${ }^{\mathrm{g}, \mathrm{h}}$, Nereyda Estrada ${ }^{\mathrm{w}}$, Rebecca J. Foster ${ }^{\mathrm{i}}$, Oscar Godínez-Gómez ${ }^{\mathrm{j}}$, Bart J. Harmsen ${ }^{\mathrm{i}}$, Christopher A. Jordan ${ }^{\mathrm{b}}$, Timothy H. Keitt ${ }^{\mathrm{k}}$, Marcella J. Kelly ${ }^{1}$, Joel Sáenz Méndez ${ }^{\mathrm{m}, \mathrm{n}}$, Eduardo Mendoza ${ }^{\mathrm{o}}$, Ninon Meyer ${ }^{\mathrm{p}}$, Gilberto Pozo Montuy ${ }^{\mathrm{q}}$, Eduardo J. Naranjo ${ }^{\mathrm{p}}$, Clayton K. Nielsen ${ }^{\mathrm{f}}$, Georgina O'Farrill ${ }^{\mathrm{u}}$, Rafael Reyna-Hurtado ${ }^{\mathrm{p}}$, Marina Rivero ${ }^{\mathrm{p}, \mathrm{r}}$, José Pablo Carvajal Sánchez ${ }^{\mathrm{m}, \mathrm{s}}$, Maggie Singleton ${ }^{\mathrm{d}}$, J. Antonio de la Torre ${ }^{\mathrm{t}, \mathrm{r}}$, Margot A. Wood ${ }^{\mathrm{v}}$, Kenneth R. Young ${ }^{\mathrm{a}}$, Jennifer A. Miller ${ }^{\mathrm{a}}$

${ }^{a}$ Department of Geography and the Environment, The University of Texas at Austin, Austin, TX 78712, USA

${ }^{\mathrm{b}}$ Global Wildlife Conservation, Austin, TX, United States of America

${ }^{\mathrm{c}}$ Department of Applied Ecology, North Carolina State University, Raleigh, NC 27695, USA

${ }^{\mathrm{d}}$ Department of Biology, Lincoln Memorial University, Harrogate, TN 37752, USA

e Nai Conservation, San José, Costa Rica

${ }^{\mathrm{f}}$ Department of Forestry and Cooperative Wildlife Research Laboratory, Southern Illinois University, Carbondale, IL 62901, USA

${ }^{\mathrm{g}}$ Programa de Evaluación y Monitoreo de la Biodiversidad, Instituto de Investigación de Recursos Biológicos Alexander von Humboldt, Colombia

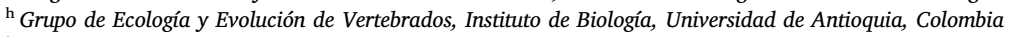

${ }^{\mathrm{i}}$ Panthera, USA

${ }^{\mathrm{j}}$ Laboratorio de Análisis y Conservación de la Biodiversidad - Instituto de Investigaciones sobre los Recursos Naturales, Universidad Michoacana de San Nicolás de Hidalgo,

Morelia, Michoacán, C.P. 58337, Mexico

${ }^{\mathrm{k}}$ Department of Integrative Biology, The University of Texas at Austin, Austin, TX 78712, USA

${ }^{1}$ Department of Fish and Wildlife Conservation, Virginia Tech, Blacksburg, VA 24061, USA

${ }^{\mathrm{m}}$ Universidad Nacional, Instituto de Conservación y Manejo de Vida Silvestre Apdo, 1350-300, Costa Rica

${ }^{\mathrm{n}}$ Centro Agronómico Tropical de Investigación y Enseñanza, Apartado 7170, Turrialba, Costa Rica

${ }^{\circ}$ Instituto de Investigaciones sobre los Recursos Naturales, Universidad Michoacana de San Nicolás de Hidalgo, Morelia, Michoacán C.P. 58330, Mexico

${ }^{\mathrm{p}}$ El Colegio de la Frontera Sur, Departamento de Conservación de la Biodiversidad, Lerma, Campeche, and San Cristobal de Las Casas, Chiapas, Mexico

${ }^{\mathrm{q}}$ Conservación de la Biodiversidad del Usumacinta A.C., Emiliano Zapata, Tabasco C.P. 86990, Mexico

${ }^{\mathrm{r}}$ Bioconciencia A.C., Ciudad de México, Mexico

${ }^{s}$ Universidad Técnica Nacional, Sede Atenas Apdo 7-4013, Costa Rica

${ }^{\mathrm{t}}$ Instituto de Ecología, UNAM, Laboratorio de Ecología y Conservación de Vertebrados Terrestres, Ap. Postal 70-275, C. P. 04510 Ciudad Universitaria, Mexico

u 3456 Joseph N. Drapeau, Montreal, Quebec H1X 3J1, Canada

${ }^{v}$ Global Synthesis, Moore Center for Science, Conservation International, 2011 Crystal Dr. Suite 500, Arlington, VA 22202, USA

${ }^{\mathrm{w}}$ Escuela de Biología, Universidad Nacional Autónoma de Honduras, Tegucigalpa, Honduras

\section{A B S T R A C T}

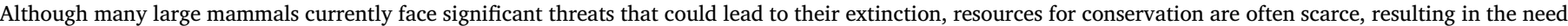

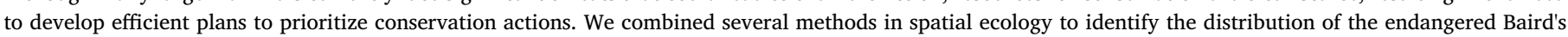

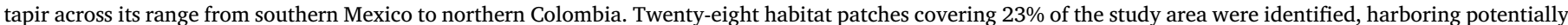

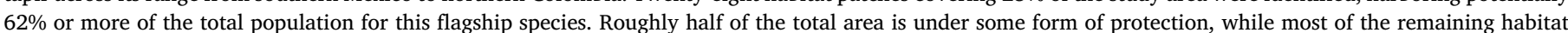

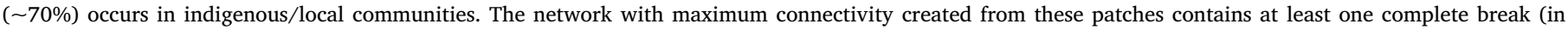

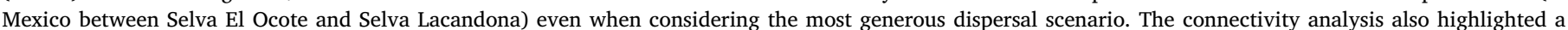

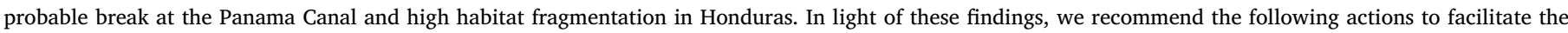

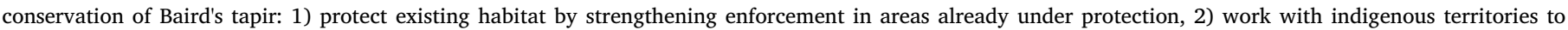

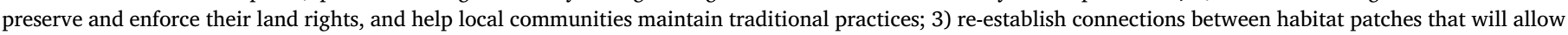

\footnotetext{
* Corresponding author at: Department of Geography and the Environment, The University of Texas at Austin, Austin, TX 78712, USA.

E-mail address: codyschank@gmail.com (C.J. Schank).
} 


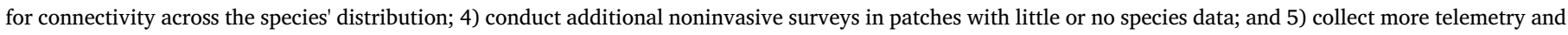
genetic data on the species to estimate home range size, dispersal capabilities, and meta-population structure.

\section{Introduction}

Approximately one quarter of mammal species are under threat, and immediate actions are needed to reduce their risk of extinction (IUCN, 2019; García et al., 2016; Schipper et al., 2008). This is especially true of large mammals, which require more habitat, are often slow reproducers, and face threats from hunting or conflict with humans (Dirzo et al., 2014). Within this group, large herbivores play a vital role in seed dispersal, nutrient cycling, and other ecosystem functions (O'Farrill et al., 2012; Ripple et al., 2015). Therefore, the loss of these species across landscapes can have cascading effects on the environment, including a reduction in the carbon storage of forests (Bello et al., 2015; Osuri et al., 2016). In addition to habitat loss, increasing habitat fragmentation leads to isolated populations that face an increased risk of extinction (Reed, 2004). Furthermore, any resultant decrease in genetic diversity can also result in negative impacts on species' viability, due to susceptibility to inbreeding or disease (Frankham, 2005).

To facilitate species conservation in response to these threats, it is necessary to create range-wide conservation plans to identify, prioritize, and direct actions to key areas (Sanderson et al., 2002). These plans consider both habitat patches and their connectivity, identifying the most important patches and corridors in need of conservation attention at both national and international levels. In most cases, this planning involves collection of expert knowledge on the species of concern (Rabinowitz and Zeller, 2010). However, many new tools now exist to make inferences about species distributions and connectivity from existing species data, and these have been shown to be more effective than expert information alone (Zeller et al., 2012). Regardless of the information used in the planning process, a range-wide perspective is important if the overall conservation of the species is the goal (Sanderson et al., 2002).

Baird's tapir (Tapirus bairdii) is the largest terrestrial herbivore native to Mesoamerica and plays an important role in ecosystems as a browser and seed disperser (Brooks et al., 1997; O'Farrill et al., 2012). However, this species is highly threatened by habitat destruction, habitat fragmentation, and poaching (Cove et al., 2014; Naranjo, 2009, 2018; Naranjo et al., 2015). As a result, it is classified as Endangered by the IUCN Red List (García et al., 2016). Additionally, tapirs are relatively unique evolutionarily, thus their extinction would represent a greater loss of genetic lineage compared to species with closer genetic relatives (Isaac et al., 2007). It is estimated that the distribution of Baird's tapir has been reduced drastically, possibly by as much as $50 \%$ in the past 30 years (García et al., 2016). More recently, the Baird's Tapir Survival Alliance was established in 2017 to facilitate the coordination of conservation efforts across the species distribution, including participants from six Central American countries and Mexico.

Species Distribution Models (SDMs) (see Table 1 - Glossary of terms) provide continuous spatial predictions on species habitat preferences, and are often based on either of two types of observational data: presence-only or presence-absence (Franklin, 2010). Integrated SDMs were developed to utilize multiple types of species data, including these two, in one model (Dorazio, 2014; Koshkina et al., 2017; Pacifici et al., 2017). Here, we combined an Integrated Species Distribution Model (ISDM) with a connectivity analysis to identify suitable habitat patches for Baird's tapirs and the critical areas required to maintain connectivity across their distributional range from southern Mexico to northern Colombia.

Previous research modeled the range-wide distribution for Baird's tapir using an ISDM (Schank et al., 2017), yet no effort has been made to assess the connectivity of the habitat patches identified, or to develop a prioritization plan for conservation action based on such an analysis. This research addresses these gaps by conducting a network analysis on the habitat patches to calculate the contribution of each patch to overall network integrity (i.e. connectedness). These measures of connectivity are combined with other indicators, including population size, protection status, and forest loss, to develop separate indices of ecological importance and vulnerability for each habitat patch. Thus, we consider two important aspects of extinction risk (i.e. importance and vulnerability) when developing a conservation plan, similar to others that previously conducted range-wide assessments (Altrichter et al., 2012; Zeller and Rabinowitz, 2011). Common SDM methods have been combined with graph networks in several instances (Albert et al., 2017; Dilts et al., 2016; Foltete et al., 2012), yet this work represents one of the first comprehensive attempts to combine ISDMs with graph networks, and to use the results to develop basic indices for conservation prioritization. Our results are used to develop a set of conservation actions for Baird's tapirs, in addition to suggestions for improvements to the models and methods used. This approach will be useful for many species that have not yet been assessed in a similar manner.

\section{Methods}

\subsection{Species data and environmental predictors}

The species data used in the ISDM come from an international collaboration among $>30$ researchers across Mexico, Central America, and Colombia. These data included approximately 800 presence-only (PO) points and 1600 sites with site-occupancy (SO) data from camera traps across 17 years, from 2000 to 2017. Details and sources of these data can be found in previous publications (Schank et al., 2015, 2017).

Due to the clustered nature of the species data, we used a random spatial subsampling (pre-modeling) step to enforce a minimum distance of $5.7 \mathrm{~km}$ between the sample locations used in the model (Schank et al., 2017). This distance was based on knowledge about the average home range for the species, with estimates that range from $1 \mathrm{~km}^{2}$ to $24 \mathrm{~km}^{2}$ (Foerster and Vaughan, 2002; Reyna-Hurtado et al., 2016). This step was performed to remove possible bias in both the PO and SO data due to individual tapirs that could be detected at more than one sample location in the complete data set. To maintain a consistent spatial scale, the pixel size of environmental predictors was matched to this process such that no two sample points could fall in the same pixel (i.e. a resolution of $4 \mathrm{~km}$, with diagonal length of $5.7 \mathrm{~km}$ ). The ISDM was trained separately on 1000 random samples generated by this process in order to capture the variability introduced by this step. Parameter estimates were then averaged across these iterations.

Environmental predictors used in the model included climate, land cover, anthropogenic disturbance, and terrain. Temperature and precipitation seasonality, maximum temperature of the warmest month, and annual precipitation were used as climate variables in the model. These variables were selected as a subset of important predictors based on earlier modeling efforts for the species (Mendoza et al., 2013; Schank et al., 2015). Climate layers were downloaded from CHELSA (Karger et al., 2017). Percentage forest cover from the year 2000 (Hansen et al., 2013), distance to/within protected areas (UNEPWCMC, 2014), mean Enhanced Vegetation Index (EVI) from years 2000-2015 (Google Earth Engine Team, 2015), and water occurrence (Pekel et al., 2016) were used as land cover variables. EVI is a remotelysensed data product calculated using information from multiple spectral bands, and meant to capture the quantity and health of vegetation. EVI is sometimes preferred over the more commonly known 
Table 1

Glossary of terms used with specific regard to species distribution modeling and landscape ecology.

Betweenness - A measure of graph centrality, betweenness is calculated as the number of times a node acts as a connection along the shortest path between two other nodes.

Conductance - The reciprocal of the more commonly used resistance layer often used with least cost analysis. The resistance represents the difficulty of moving through a landscape for a species.

Effective sample area - The area that contains the activity centers of any individuals of a species that are available to come into contact with detectors (e.g., camera traps).

Enhanced vegetation index - EVI is a remotely-sensed data product calculated using information from multiple spectral bands, and meant to capture the quantity and health of vegetation. This index is sometimes preferred over the more commonly known Normalized Difference Vegetation Index (NDVI) because it is more sensitive to differences in canopy structure in forested areas.

Farness - A measure of graph centrality, farness is the sum of all of the distances between a given node and all of the nodes it is connected to. Closeness is the reciprocal of farness.

Graphs - Used across a wide variety of applications (from Linguistics to Social Sciences), graphs consist of nodes (points) and the edges which connect them. A component is a distinct unit of a graph with no breaks in connectivity.

Hotspot analysis - An analysis focused on the identification of clusters of spatial objects. In this paper we used the Getis-Ord Gi* method to delineate habitat patches as clusters of habitat with high intensity values.

Importance index - A patch-level index formulated in this paper which is the summation of: population index (max estimated population $=1$ ), confirmed presence of the species (from either observational data type), graph betweenness, and graph components created by removing the patch. All four of these measures were scaled to range from 0 to 1 prior to summing.

Integrated Species Distribution Models (ISDMs) - ISDMs were developed to utilize multiple types of species data in the same model, including presence-only and site occupancy data.

Least-cost path - The most 'cost effective' path between two points taking into account a resistance layer. This is because the shortest path between two points is not always the easiest (e.g. Euclidean straight line distances), especially for species traversing a fragmented landscape.

Dispersal kernel - A probability density function representing the probability that a species will disperse within a given distance.

Poisson point process - Used across a variety of applications (from Astronomy to Epidemiology), Poisson point process models are formulated to estimate the count of some phenomenon across a unit of area (often referred to as intensity).

Population Viability Assessment (PVA) - Analysis to estimate the probability of species extinction in a given time period or to predict the outcomes of management/conservation applications, usually based on life history traits and mathematical models.

Presence-only data - Contains information only about the species presence (there are no observations of species absence). This is the most readily available type of data used in SDMs, as it is often compiled from museum specimens or other sources.

Probability of detection - The probability of detecting at least one individual of a species of interest with a detector in an array, given the species is present and available for detection.

Spatial Capture-Recapture (SCR) - A spatial extension of classic capture-recapture in which data from individuals' detections are used to estimate population density and individual-specific movement and baseline detection.

Site occupancy data - Repeated detection/non-detection data of a target species, usually from noninvasive detector (e.g., camera trap or acoustic monitor, etc.) arrays.

Species Distribution Models (SDMs) - Provide continuous spatial predictions on species habitat preferences, and are often based on either of two types of observational data: presence-only or presence-absence.

Vulnerability index - A patch-level index formulated in this paper which is the summation of: the percent of unprotected land, the rate of deforestation, the reciprocal of a population index (higher numbers represent smaller populations), and farness. All four of these measures were scaled to range from 0 to 1 prior to summing.

Normalized Difference Vegetation Index (NDVI) because it is more sensitive to differences in canopy structure in forested areas (Huete et al., 1997). Forest loss (Hansen et al., 2013) and fire frequency (NASA, 2017), between 2000 and 2016, and road density (Eugster and Schlesinger, 2010) were used as indicators of anthropogenic disturbance. Finally, slope was used to incorporate the effect of terrain; this variable was calculated from $90 \mathrm{~m}$ resolution elevation data (i.e.
SRTM) downloaded from the 'raster' package in R (Hijmans et al., 2016).

The ISDM also incorporated variables that could influence the detectability of the species, which allowed the creation of a separate set of detectability variables for the two different types of species data used in the model (i.e. PO and SO). For the PO data, these variables included binary indicators for forest (Arino et al., 2012) and protected status (UNEP-WCMC, 2014), distance to roads (Eugster and Schlesinger, 2010), and slope. Variables for SO data incorporated land cover and anthropogenic disturbance, as well as distance to roads, slope, and dummy variables for different sampling methods (on- vs off-trail and surveys targeting tapirs, large cats, or general biodiversity inventories). These last variables were included to control for the different sampling regimes used by the various sources of species data. Variables used with PO data were meant to capture sampling bias, which heavily favors forested and protected areas that are reasonably accessible by road. A quadratic term for distance to roads was also used, as there could be optimal locations that are far enough from roads to minimize anthropogenic factors, but close enough to facilitate sampling. With SO data, the sampling variables were chosen as variables that might influence the detectability of the species. For example, tapir detectability might decrease as distance from protected areas increases, due to avoidance of humans as result of heightened levels of hunting outside of protected areas (de la Torre et al., 2018; Ferreguetti et al., 2017).

All variables were resampled to a resolution of $4 \mathrm{~km}$, scaled (standard deviation $=1$ ) and centered on zero (mean $=0$ ), except for distance to/within protected areas, which was scaled but not centered. This was done to preserve zero as the boundary between inside (negative values) versus outside (positive values) of the protected area. Quadratic terms for all climate variables, EVI, water occurrence, and distance to roads were used in the model to account for their suspected non-monotonic relationships with tapir presence and detectability (aided by single-variable response curves created in the early stages of the modeling process).

\subsection{Integrated SDM}

This research used an Integrated SDM (ISDM) to incorporate both opportunistically collected presence-only (PO) data and site-occupancy (SO) data from planned surveys. The ISDM uses a hierarchical framework to estimate separately species occurrence and detectability. Species occurrence is modeled as the intensity of a Poisson point process, $\lambda(s)$, which is the expected density (number of individuals per unit area) at location $s$. The intensity is formulated as a log-linear function of unknown parameters and location-specific regressors $x(s)$,

$\log (\lambda(s))=\beta_{0}+\beta^{\prime} x(s)$

In the ISDM, separate detectability formulations were used for the two types of data. For the PO data, spatial bias and imperfect detection are incorporated through an independent thinning of the point process. This thinned point process is the product of the original point process and $p_{p o}(s)$, the probability that the site is surveyed and the species is detected, which is formulated as a logistic function of unknown parameters and location-specific regressors $w_{p o}(s)$,

$\operatorname{logit}\left(p_{p o}(s)\right)=\alpha_{0 . p o}+\alpha_{p o} w_{p o}(s)$

With the SO data, imperfect detection is modeled following the design of a conventional occupancy model (Koshkina et al., 2017; MacKenzie et al., 2002; Tyre et al., 2003). Under this model, the presence or absence of the species at a site, $i$, follows a Bernoulli distribution. In this case, the detection histories at each site, $y_{i}$, have nondetections (i.e. zeros) due to either species absence or imperfect detectability, when an individual may go undetected despite being present (MacKenzie et al., 2003). This relationship is modeled as a Binomial distribution with $J$ trials (i.e. the number of repeated observations 
at a site), and the probability of success (i.e. species detection) equal to the product of $z_{i}$ (the occupancy state, $z_{i}=I\left(N_{i}>0\right)$ ) and $p_{p a}$, the probability of detection at the site. As with detectability in the PO model, $p_{s o}(s)$ is formulated as a logistic function of unknown parameters and location-specific regressors $w_{s o}(s)$,

$\operatorname{logit}\left(p_{s o}(s)\right)=\alpha_{0 . s o}+\alpha_{s o}{ }^{\prime} w_{s o}(s)$

In ISDMs, the PO and SO models are estimated simultaneously, such that one set of parameters for the SDM is created (i.e. the $\beta$ 's), while separate detectability parameters are estimated (i.e the $\alpha$ 's) for the two models. Starting values for both detectability intercepts (i.e. $\alpha_{\text {o.po }}$ and $\alpha_{O . s o}$ ) were set to the naive detectability for each respective data type to help solve issues with model convergence. All other parameters in the model used a starting value of zero. The intensity estimates from the ISDM can be integrated across a spatial unit to estimate the expected number of individuals in that area. This property is used to estimate population sizes in the habitat patches identified by the analysis.

The ISDM requires knowledge of the area sampled at each site in order to estimate intensity. We assumed an Effective Sample Area (ESA) of $16 \mathrm{~km}^{2}$, which is close to the most recent home range estimates for the species, depending on the method used (i.e. kernel density estimation: home ranges of 15.0 and $13.6 \mathrm{~km}^{2}$, for two individuals) (Jordan et al., 2019) and about midway between previous estimates (Foerster and Vaughan, 2002; Reyna-Hurtado et al., 2016). This area also matches the resolution of environmental predictors used in the model (i.e. resolution of $4 \mathrm{~km}=16 \mathrm{~km}^{2}$ ).

The ISDM was fit using custom $\mathrm{R}$ code adapted from previous research (Dorazio, 2014; Schank et al., 2017, 2019).

\subsection{Quantifying habitat connectivity}

The estimated intensity surface was converted to a map of habitat patches using a hotspot analysis. Specifically, the Getis-Ord Gi* (i.e. local $G$ ) spatial statistic (Getis and Ord, 1992) was calculated using a $10 \mathrm{~km}$ radius, and statistically significant hotspots designated as habitat patches for the species. This threshold was selected as the maximum recorded distance traveled by an individual tapir within its home range (Reyna-Hurtado et al., 2016), thus accounting for a level of interactivity between individuals that could be representative of a habitat patch.

The estimated intensity was then summed within these patches, and those with an estimated population of 10 or more were retained for the next stages of the analysis. Researchers in the Atlantic Forest of Brazil estimated that 200 adult individuals of Tapirus terrestris are needed to constitute a minimum viable population (Medici and Desbiez, 2012). Rather than using 200 individuals as the cut off for our habitat patches, we used the minimum population from different test scenarios carried out in a Population Viability Assessment (PVA) for Baird's Tapir (Medici et al., 2005). We did this in order to maximize the number of vertices in the network (within reason), while considering that some patches may act as population sinks (i.e. they harbor less than a viable population, and thus are reliant on immigration of individuals from adjacent patches to prevent local extinction). In the PVA, in nearly all scenarios, a population of ten individuals had a $>50 \%$ probability of going extinct within 100 years. However, these scenarios did not consider immigration and other meta-population dynamics.

An estimate of flow between patches was created by first calculating the least-cost distance between pixels with the intensity surface as a transition layer (i.e. conductance) using the R package 'gDistance', and the ShortestPath function (van Etten, 2017). Only those connections with distances less than an estimated maximum dispersal distance were

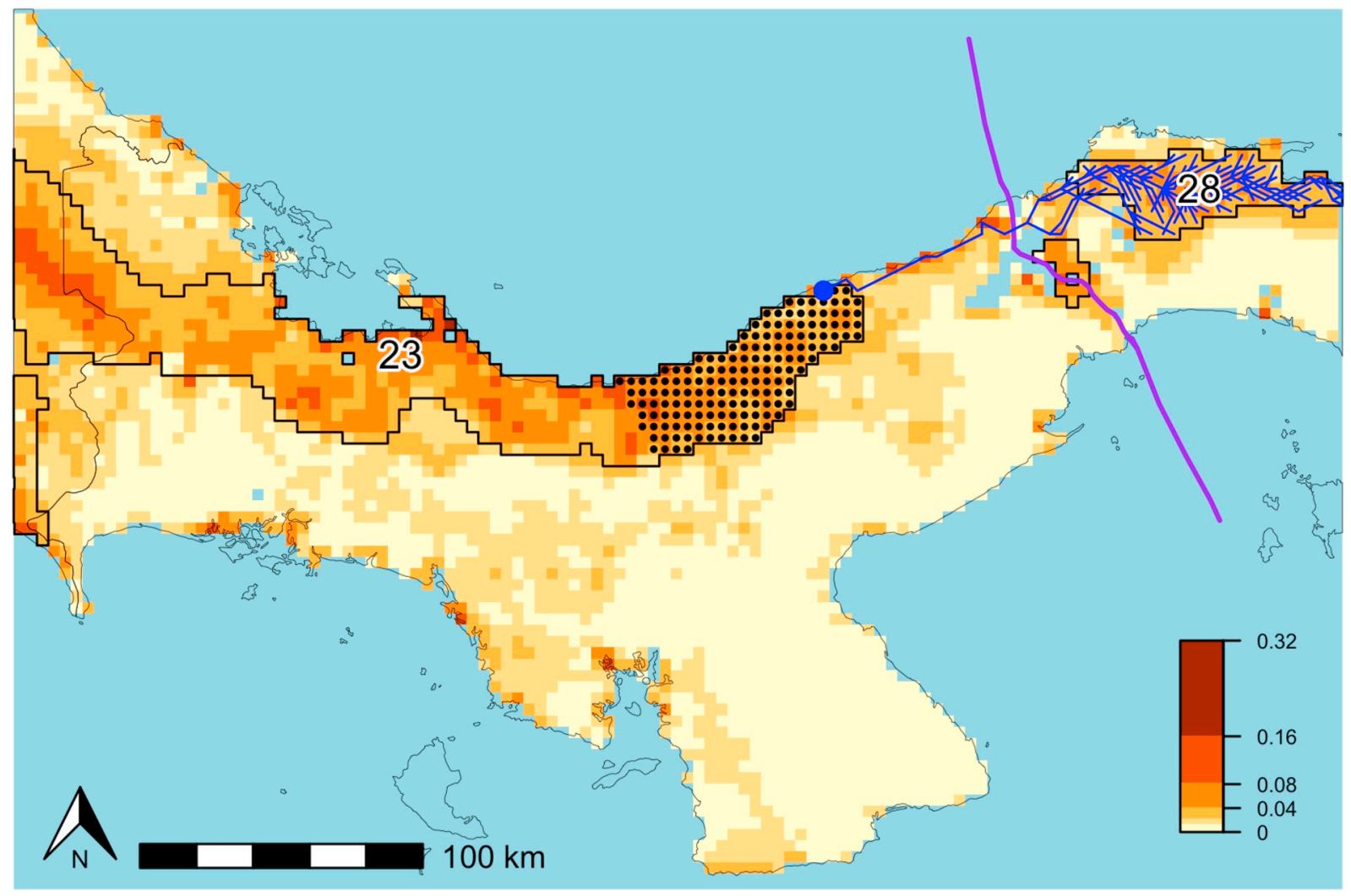

Fig. 1. Example of ow calculation for one source pixel going from patch 23 to patch 28 . Black dots are additional pixels that fall within range of the destination patch, and will subsequently have least cost paths (LCPs) and ow calculated. Blue lines are LCPs, purple line is the Panama Canal, estimated tapir density (individuals/km2) shown in shades of brown. See Fig. 2 for locational context within region. (For interpretation of the references to colour in this figure legend, the reader is referred to the web version of this article.) 
retained, calculated as 40 times the linear dimension of the home range estimate. This relationship between home range size and dispersal was determined by a correlative study of 33 species of North American mammals, with maximum recorded dispersal up to $500 \mathrm{~km}$ (Bowman et al., 2002). Due to the variability in home range estimates, three maximum dispersal distances were tested: 40, 80, and $160 \mathrm{~km}$ (corresponding to home ranges of 1,4 , and $16 \mathrm{~km}^{2}$ ) (Foerster and Vaughan, 2002; Jordan et al., 2019; Reyna-Hurtado et al., 2016). In contrast to the $10 \mathrm{~km}$ distance used in the hotspot analysis, which was selected to be representative of daily movement patterns, these dispersal scenarios are more theoretical (due to lack of empirical data), and meant to represent the long-distance dispersal abilities of the species in seeking out and establishing new home ranges.

The least-cost distance was then used in a negative exponential dispersal kernel (Nathan et al., 2012):

$\left(1 / 2 \pi a^{2}\right) *(\exp (-r / a))$

where $a$ is two times the mean dispersal distance and $r$ is the least-cost distance between pixels.

The median dispersal distance was used in place of the mean, which was estimated as seven times the linear dimension of the home range (Bowman et al., 2002). Finally, this dispersal probability was multiplied by the square root of the estimated intensity in the source pixel, and used to estimate the flow between pixels (Estrada and Bodin, 2008). For each pair of adjacent patches (i.e. nodes in the graph), the corresponding flow between their respective pixels was summed and stored as the singular edge value between that pair of nodes (see Fig. 1 for a map documenting this step). This flow matrix was used to create a weighted and directed graph network with the R package 'igraph' (Csardi and Nepusz, 2006).

Using this graph network, two measures of vertex centrality were calculated: farness and betweenness. Farness (i.e. the inverse of closeness) was defined as the average length of the shortest paths from all other vertices in the graph (Brunn, 2011). This measure was then used to represent the isolation of individual patches in the indices calculated. Vertex betweenness is roughly defined as the number of shortest paths going through a given vertex (Brunn, 2011). This measure was used to represent the importance of a given patch to the overall connectivity of the network. Each vertex was then removed from the graph one at a time, and the number of components (i.e. isolated subgraphs) recorded. This was done to identify when new components were created by removing the vertex, indicating a new break in the graph.

\subsection{Prioritization criteria}

To prioritize the different patches for conservation, our goal was to balance vulnerability to local extinctions and importance to the survival of the species as a whole. For this reason, two separate indices were

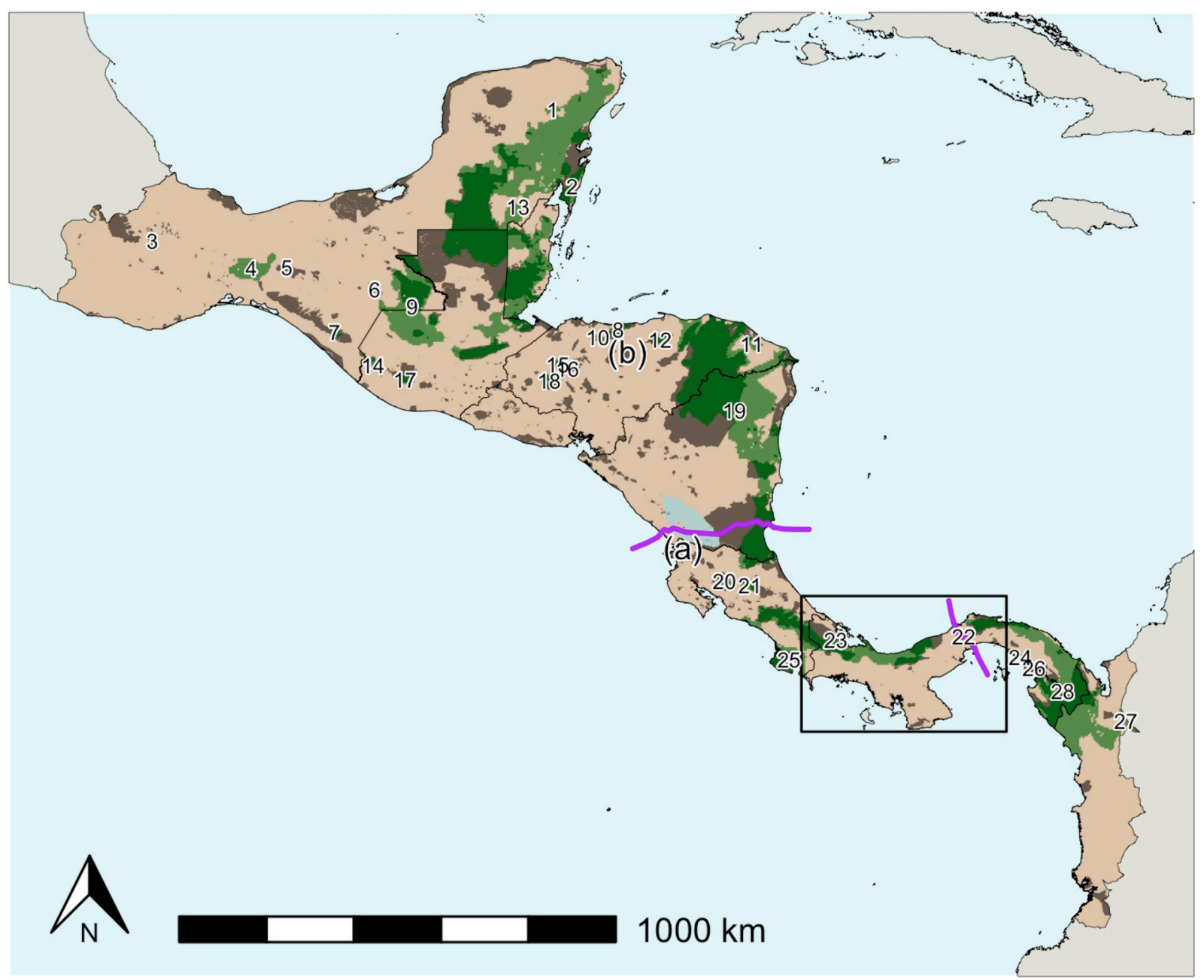

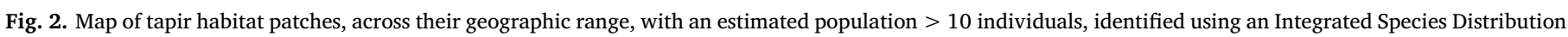

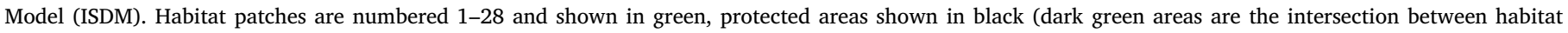

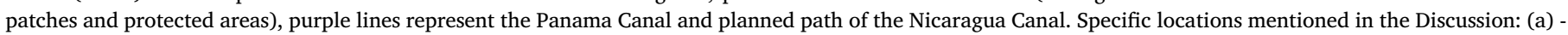

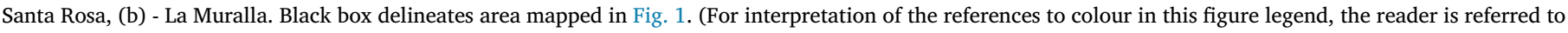
the web version of this article.) 
calculated for each patch and then combined for an overall index of conservation priority.

Before calculating these indices, some initial measures were created and used in the subsequent calculations: 1) the percentage of each patch that was not under protection (UNEP-WCMC, 2014); 2) a population index that converted the estimated population in each patch to a scale of 0 to $1 ; 3$ ) evidence of occupation by the species using both PO and SO data (binary: 0 or 1); and 4) an index of forest loss occurring in the patch (Hansen et al., 2013). Population size provides information about both the vulnerability and ecological importance of a patch, while level of protection and amount of forest loss occurring in the patch are informative about vulnerability. Confirming the species presence in a patch provides more confidence in its ecological importance, as there are likely some patches (especially small ones) that incorrectly predict species presence. These patches do have value for species conservation (e.g. for translocations, or re-establishment of connectivity), but perhaps less than if already occupied.

The vulnerability index was calculated to represent the relative risk of a local extinction for a given habitat patch. Less protection, more deforestation, smaller populations, and greater distance from other patches in the network should lead to cores that are more vulnerable. Thus, this index was created as the sum of the following:

$\%$ unprotected + deforestation $+(1 /$ population index $)+$ farness

The importance index was created to represent the relative importance of a given habitat patch to the overall survival of the species. Larger estimated populations, confirmed presence of the species, and importance to the overall network connectivity should indicate patches that had greater importance. Thus, this index was calculated as the sum of the following:

\section{population index + confirmed presence + betweenness index}

\section{+ components created by removal}

All components used in the vulnerability and importance indices were rescaled to range from 0 to 1 . The vulnerability and importance indices were then also rescaled to have a max value of 1 , before summing them into the combined index of conservation priority. It is important to note that the population measures used in these two indices will cancel each other out when combined. However, they are useful to include when considering vulnerability and importance separately. Similarly, the centrality measures will have some counteracting effect when combined, but the relationship between these is not exactly reciprocal.

\section{Results}

Significant environmental variables to model the intensity of Baird's
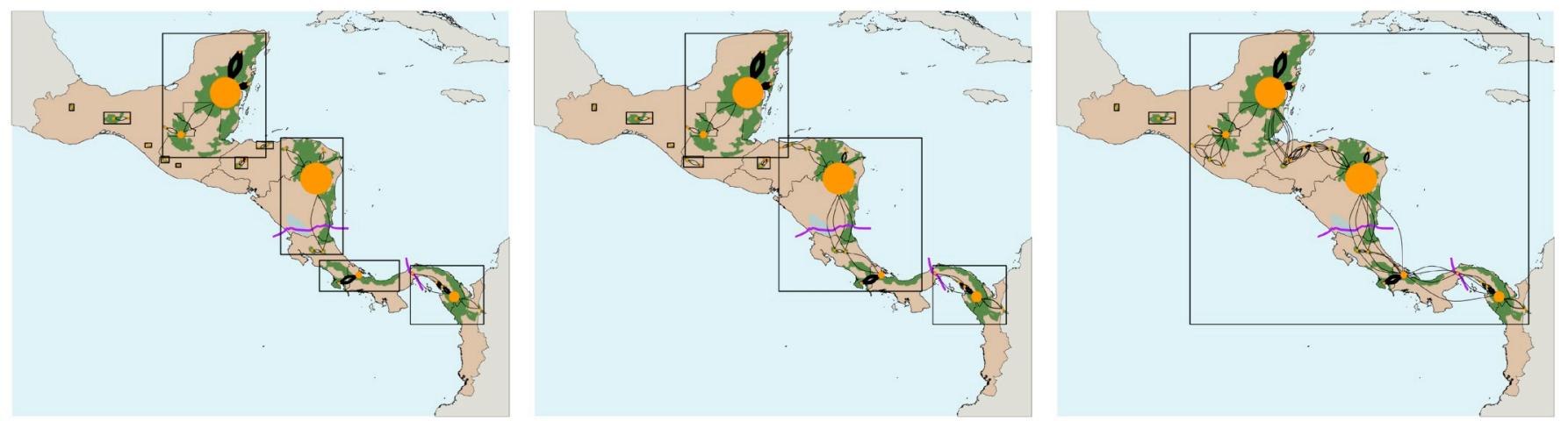

(a) Max dispersal $=40 \mathrm{~km}$, components $=11$

(b) Max dispersal $=80 \mathrm{~km}$, components $=8$ tapir (i.e. 95\% CI excluding 0; Supplementary Table 1) included water occurrence (1.44, SE $=0.45$ ), forest cover $(1.33$, SE $=0.20)$, annual precipitation $(1.20, \mathrm{SE}=0.34)$, EVI $(-0.56, \mathrm{SE}=0.17)$, and temperature seasonality $(-0.44, \mathrm{SE}=0.13)$. Significant quadratic terms for water occurrence $(-0.84, \mathrm{SE}=0.34)$, temperature seasonality $(-0.39, \mathrm{SE}=0.12)$ and annual precipitation $(-0.81, \mathrm{SE}=0.26)$ indicated possible non-monotonic relationships for those variables. A 3dimensional response curve for the interaction between forest cover and EVI demonstrated highest lambda values when high forest cover was combined with low EVI (Supplement Fig. 1). Significant variables to model the detectability of tapir using presence-only (PO) data (Supplementary Table 1) included presence in a protected area (1.35, $\mathrm{SE}=0.24)$ and distance to roads $(-0.43, \mathrm{SE}=0.15)$. With the SO data, the dummy variable for surveys targeting tapirs was significant (1.04, SE $=0.44)$.

Average estimated intensity from the model was 1.85 individuals/ $100 \mathrm{~km}^{2}$, with a maximum of 47.1 individuals $/ 100 \mathrm{~km}^{2}$. The hotspot analysis identified 28 habitat patches with an estimated population of 10 or more individuals (Fig. 2). These patches covered $23.3 \%$ of the land in the study area, and contained an estimated total of 10,343 individuals, $61.6 \%$ of the total population estimated across the entire study area.

The three dispersal scenarios showed varying levels of connectivity (Fig. 3). In the most restrictive case (max dispersal $=40 \mathrm{~km}$ ), the network contains several disruptions in connectivity, with eleven separated graph components. Even the most generous dispersal scenario (max dispersal $=160 \mathrm{~km}$ ) is separated into three distinct components. While the medium dispersal scenario (max dispersal $=80 \mathrm{~km}$ ) resulted in eight components. Across all three dispersal scenarios, a low degree of connectivity occurred at the extreme northwestern edge of the distribution, with completely isolated patches in Oaxaca (ID 3) and Selva Zoque (ID 4,5) México. In the moderate scenario (max dispersal $=80 \mathrm{~km}$ ), additional breaks in connectivity emerged across Honduras and at the Panama Canal.

Focusing on the indices calculated using the most generous dispersal scenario (in order to consider the impact of potential connections), the most vulnerable habitat patch was found in the northern Yucatan Peninsula (ID 1). This patch had a small estimated population $(\sim 14$ individuals), is completely unprotected, and had a high level of isolation (i.e. farness) from other patches (Supplementary Table 2). The four most vulnerable patches had low importance values, with small estimated populations (mean $=19.5$ individuals), no confirmed tapir presence, and low contribution to connectivity. The two patches with the largest estimated population, Maya Forest (ID 13) and Honduras (Moskitia)-Nicaragua (ID 19), also had the highest combined index (i.e. vulnerability + importance), and had an important role in connectivity (Fig. 4).

Fig. 3. Maps of network connectivity. Thickness of edges indicates strength of ow between vertices, size of nodes indicates estimated population size. Boxes delineate separated graph components. 


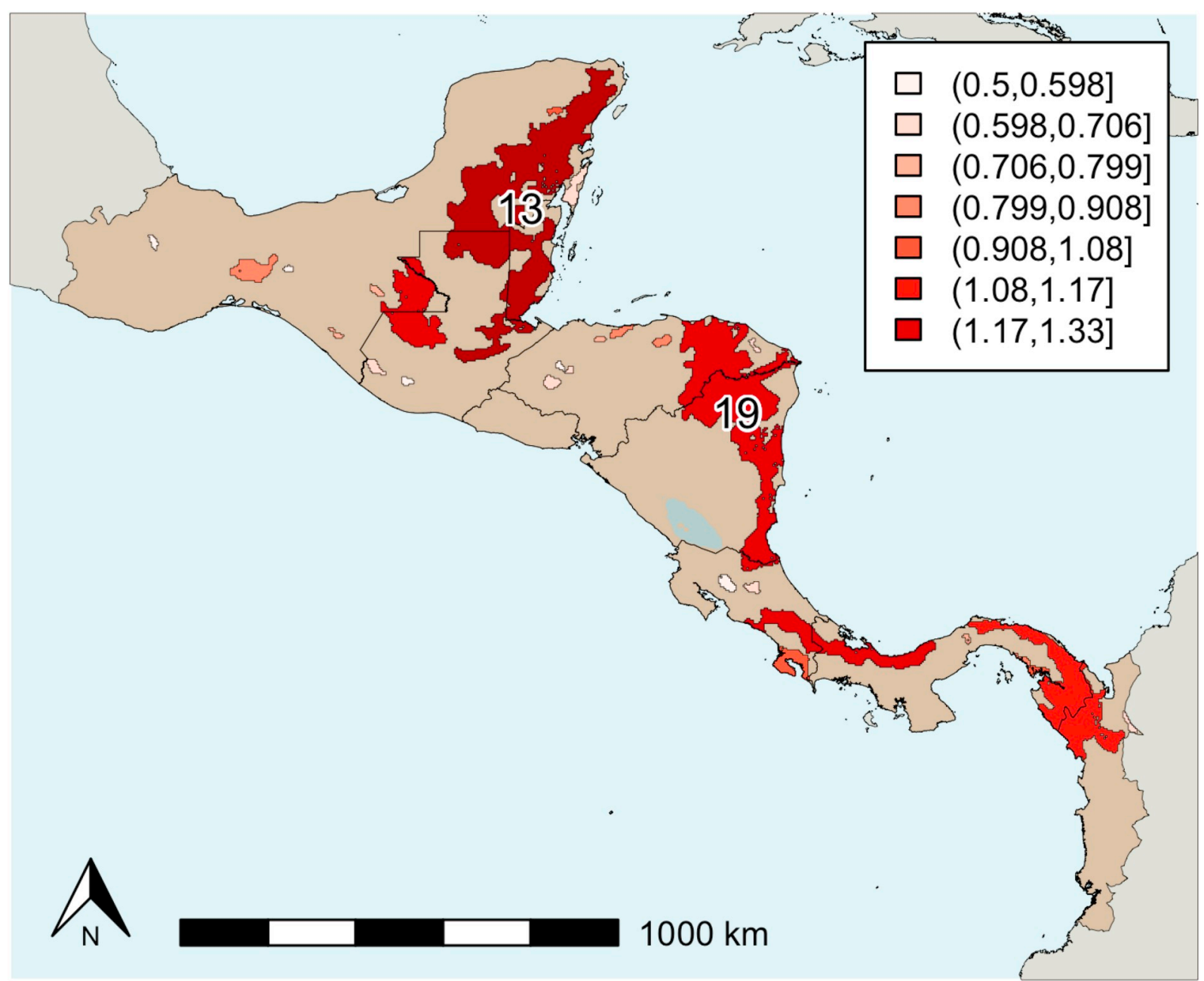

Fig. 4. Choropleth map of combined indices (max dispersal $=160 \mathrm{~km}$ ).

About half $(49.1 \%)$ of the total area covered by the habitat patches has some form of protected status. Much of the remaining area (71\%) occurs in indigenous territories, including Chimalapas in Mexico (ID 5), Honduras(Moskitia)-Nicaragua (ID 19), and between Chagres and Darien National Parks in Panama (ID 28). The latter includes the Darien region of northern Colombia, a significant area that is unprotected and not under indigenous control. However, this area has remained largely undeveloped due to the harsh environment and armed conflict between the government and paramilitary groups (Girot, 2002; Grajales, 2013).

IUCN recently produced a map of indigenous territories in Central America (IUCN-ORMACC, 2016). Focusing on these countries (i.e. excluding Colombia and Mexico), $88.0 \%$ of tapir patches are either protected or in an indigenous area. This includes the Qeqchi (Kekchi) in Guatemala, Miskito and Tawahkas in Rio Platano (Honduras), Miskito and Ulwa in northern Nicaragua, Ngäbe-Buglé in Golfo de los Mosquitos Panamá, and Guna and Embera-Wounaan near Chagres and Darien, Panama.

\section{Discussion}

This research represents the first study to model the distribution and connectivity of Baird's tapir habitat and populations across its entire geographic range. All of the significant parameter estimates from the model (and even those that were close to significant), exhibited the expected relationships with tapir intensity. In previous studies, the negative relationship with EVI was unexpected (Schank et al., 2017). However, after examining the interaction between EVI and forest cover, it was clear that the model demonstrates evidence of tapir preference for secondary forest, as these are areas which would show up with high forest cover, but relatively lower biomass (Foerster and Vaughan, 2002; Fragoso, 1983). The hump-shaped relationship with annual precipitation is likely what drives the low estimates of tapir presence in the Chocó, one of the wettest areas globally, and where rainfall is much higher than the rest of the study area (mean rainfall twice as high as any other portion of the study area) (Schwerdtfeger, 1976).

It is important to note that the resolution of the analysis can have significant effects on the results, for both the ISDM and the connectivity (i.e. least-cost) analysis (Etherington, 2016; Schank et al., 2019). We selected a resolution we deemed appropriate for the ISDM, but future research would benefit from further evaluating this choice for the leastcost path analysis. Indeed, some connectivity research suggests using a smaller resolution closer to the species' perceptual range (Bélisle, 2005), but as a first examination of connectivity across the global distribution of Baird's tapirs we preferred to use a more liberal approach given the uncertainties of tapir movement. Likewise, we assumed that the intensity estimated by the ISDM is a proxy for suitability of movement through the landscape (i.e. conductance). Some studies have shown that habitat preferences for home ranges may differ from the species' ability to move through different types of landscapes (Elliot et al., 2014; Gastón et al., 2016; Keeley et al., 2017). Future efforts that combine SDMs with connectivity analysis will likely produce more accurate assessments if they consider appropriate resolutions for both aspects of the analyses, as well as developing a conductance or resistance layer separately from the SDM. 
As a result of our modeling approach, the results from this research almost certainly represent a best-case scenario in the distribution and extent of habitat patches for Baird's tapirs. Though there are a few underestimated areas that do not show up as suitable despite confirmed tapir occurrence (e.g. dry forests of Santa Rosa, Costa Rica, and most of the Sierra Madre de Chiapas in Southern Mexico), the overall estimated intensity and resulting habitat patches likely represent an overestimate of the species' true distribution. This overly optimistic result can be attributed to multiple factors, including the use of forest cover from the year 2000 in the model (even though forest loss in the intervening years is also used), and land cover is changing rapidly across much of Mexico and Central America.

In addition, the connectivity between cores is likely overestimated in many cases. Very little is known about the long-distance dispersal capabilities for this species. The ability of Baird's tapir to disperse even $40 \mathrm{~km}$ is questionable, especially across the low suitability habitat it would encounter when moving between most patches. Even in the most optimistic scenario, there is an alarming lack of connectivity and suitable habitat, with tenuous connections across Honduras, and a clear break in Mexico. Genetic data from jaguars revealed limited connectivity between La Selva Maya and Honduras (Wultsch et al., 2016), and these large carnivores have much greater dispersal capacity compared to tapirs. Additionally, our analysis does not incorporate potential barriers to dispersal, such as the highly developed and urbanised Panama Canal Zone and the increasing numbers of highways across southern Mexico and Central America. The planned Nicaragua Canal could present an additional dispersal barrier for the species (Jordan et al., 2016). Assuming this canal may still be built, and both it and the Panama Canal act as barriers to dispersal, while also including the breaks in the network that already exist, there is a potential for five major areas of tapir habitat to become isolated from one another. This would have significant adverse impacts on the long-term survival of the species. Isolating populations makes local extinctions more likely, due to reduced genetic diversity and interruption of meta-population dynamics (Pardini et al., 2010).

In light of these results, we recommend the following conservation actions for the species: 1) protect existing habitat, 2) work with indigenous territories and local communities, 3) re-establish and strengthen habitat connectivity, 4) conduct additional surveys of tapir occurrence, and 5) collect additional telemetry and genetic data.

\subsection{Protect existing habitat}

Our results showed that about half of the remaining habitat for Baird's tapir can be found in protected areas. Though these areas are protected (at least on paper), many of them still experience substantial deforestation inside park boundaries (Bray et al., 2008; Joppa et al., 2008; Watsa, 2014). In fact, even when deforestation is not evident from satellite imagery, these protected areas still experience significant levels of poaching and smaller scale deforestation that can have strong negative impacts on endangered wildlife and ecosystem processes (Benítez-López et al., 2019; Peres et al., 2006). Of the nearly 328 protected areas that intersect tapir habitat, 43 have experienced deforestation rates $>5 \%$ over the last 13 years, with almost half of these found in Guatemala (Table 2). This widespread habitat loss within seemingly large areas of core tapir habitat is the greatest threat to tapir conservation. Stopping and reversing this deforestation should be the number one priority for tapir conservation. Encouragingly enough, tapir use of secondary forests could result in a positive feedback loop, particularly since tapirs can facilitate reforestation via seed dispersal. In the absence of achieving this goal, all additional priorities listed below could be meaningless.

While there is very little literature on the illegal trade and poaching of Baird's tapirs, the information that does exist is extremely troubling and indicates that both pose a significant threat to tapirs throughout their range. For example, the number of tapirs poached in the
Caribbean Coast of Nicaragua over the past two decades has spiked significantly alongside sharp increases of deforestation (Jordan et al., 2014). The national and international trade of juvenile tapirs has anecdotally increased in certain Central American countries in recent years. In Nicaragua, four instances of juvenile tapirs for sale in Managua were reported between June 2017 and June 2018 without an adequate government response (C. Jordan, pers. obs.).

Perhaps even more troubling is that in countries with substantial environmental infrastructure, such as Costa Rica, legal cases against tapir poachers are usually thrown out before reaching trial and are not considered a priority by local judges (E. Brenes-Mora, pers. obs.). Anecdotal data suggests that multiple tapirs trafficked in the Nicaraguan capital of Managua in 2017 were not confiscated despite the Ministry of Natural Resources being made aware of these environmental crimes. Likewise, environmental criminals destroying core protected areas have not been held legally accountable in Nicaragua (Salazar, 2018).

\section{Table 2}

Forest loss rates (2000-2014), protected status, area, and location of protected areas that intersect tapir habitat patches.

\begin{tabular}{|c|c|c|c|}
\hline Patch ID & Name & Forest Loss & Area (sq km) \\
\hline 13 & Nim Li Punit & 0.378858025 & $0.4915825 \mathbb{B E}-\mathrm{TOL}$ \\
\hline 19 & Cerro Bana Cruz & 0.162583509 & 270.3010478 NI-AN \\
\hline 13 & Santa Rosa & 0.157021605 & $5.076279027 \mathrm{~T}-\mathrm{IZ}$ \\
\hline 19 & Cerro Wawashang & 0.156177855 & $2244.640531 \quad$ NI-AS \\
\hline 13 & Rio Blanco & 0.13117284 & $0.3814514378-\mathrm{TOL}$ \\
\hline 13 & Mountain Pine Ridge & 0.126817692 & 432.7437456 BZ-CY \\
\hline 13 & Yaxhá & 0.126157407 & $1.981078183 T-\mathrm{PE}$ \\
\hline 19 & Punta Gorda & 0.118480136 & 636.9444969 NI-AS \\
\hline 13 & Candilejas & 0.118441358 & $0.697987502 \Gamma-\mathrm{IZ}$ \\
\hline 13 & Serpon Sugar Mill & 0.105709877 & $0.522440408-S C$ \\
\hline 19 & Cerro Silva & 0.096712187 & 2921.966879 NI-AS \\
\hline 19 & Laguna de Bacalar & 0.095743203 & 72.6997879 Not Reported \\
\hline 13 & Hacienda Pastores & 0.092592593 & $0.354705878 \Gamma-B V$ \\
\hline 13 & $\begin{array}{l}\text { Parque Nacional } \\
\text { Yaxhá-Nakum- } \\
\text { Naranjo }\end{array}$ & 0.091406045 & 4874.454459 GT-PE \\
\hline 9,13 & Maya & 0.089635779 & 20,382.32075 GT-PE \\
\hline 13 & El Pujol fracción C & 0.087191358 & $0.90190386 G \mathrm{~T}-\mathrm{IZ}$ \\
\hline 9 & El Recuerdo & 0.087191358 & $0.2388245860 t$ Reported \\
\hline 13 & $\begin{array}{l}\text { Mischner \& Bowen } \\
\text { Reserve }\end{array}$ & 0.084924769 & 6.972033473Z-BZ/BZ-BZ \\
\hline 13 & Cástulo & 0.082063645 & $3.5867991666 \mathrm{~T}-\mathrm{IZ}$ \\
\hline 19 & Cerro Cola Blanca & 0.080461502 & 104.9085652 NI-AN \\
\hline 13 & Laguna del Tigre & 0.080043744 & 2895.067801 GT-PE \\
\hline 13 & Cerro San Gil & 0.079541963 & 437.5315823 GT-IZ \\
\hline 9,13 & Maya & 0.078348592 & 7549.039748 GT-PE \\
\hline 13 & El Higuerito & 0.076260288 & 6.7795830991-IZ \\
\hline 9 & Laguna Lachuá & 0.07374165 & 512.1734806 GT-AV \\
\hline 19 & Sierra de Río Tinto & 0.070898747 & 880.7079495 HN-CL \\
\hline 13 & Grants Works & 0.069741477 & 32.0053981BZ-SC \\
\hline 19 & Patuca & 0.069260159 & 3755.980622 HN-OL \\
\hline 19 & Cerro Saslaya & 0.068908179 & 631.0929706 NI-JI \\
\hline 28 & Canglón & 0.068731901 & 320.8715887 PA-5 \\
\hline 13 & $\begin{array}{l}\text { Montañas Mayas } \\
\text { Chiquibul }\end{array}$ & 0.067786102 & 615.0653551 GT-PE \\
\hline 19 & Tawahka Asangni & 0.065134896 & 2508.785858 HN-OL \\
\hline 13 & Caracol & 0.062403549 & 103.1943585 BZ-CY \\
\hline 9 & Sierra del Lacandón & 0.061744075 & 2002.866758 GT-PE \\
\hline 9 & $\begin{array}{l}\text { Empalme Santa } \\
\text { Felícitas }\end{array}$ & 0.061192996 & 42.72065462MX-СНP \\
\hline 13 & Swasey Bladen & 0.061167228 & 59.81300484BZ-TOL \\
\hline 13 & Laguna Ik & 0.058145849 & 287.8190463 MX-САM \\
\hline 13 & Río Sarstun & 0.057751956 & 324.1270458 GT-IZ \\
\hline 19 & $\begin{array}{l}\text { Fortaleza la } \\
\text { Inmaculada } \\
\text { Concepción de María. }\end{array}$ & 0.056949531 & 35.8154780 NII-SJ \\
\hline 13 & $\begin{array}{l}\text { Otoch Ma'ax Yetel } \\
\text { Kooh }\end{array}$ & 0.055748211 & 53.7212954IMX-ROO \\
\hline 13 & Río Zarco Chiquito & 0.052469136 & 0.633935739T-IZ \\
\hline 14 & Buenos Aires & 0.052276235 & $8.748731926 \mathrm{~T}-\mathrm{RE}$ \\
\hline 13 & Santa Elena & 0.050540123 & $1.406058426 \mathrm{~T}-\mathrm{IZ}$ \\
\hline
\end{tabular}


High-level lobbying by nationals to encourage governments to prioritize protected area management and the sentencing of environmental criminals is needed in most countries across Baird's tapir range. In many cases, however, the government agencies tasked with monitoring and enforcing laws within protected areas have too little money or power to do their jobs effectively (Balmford and Whitten, 2003; Bruner et al., 2004). Working with these agencies to provide the training, support, and resources to improve their effectiveness and thereby reduce deforestation, poaching and trafficking should be a priority. The Spatial Monitoring and Report Tool (SMART) is an opensource software program designed to facilitate the collection, analysis, and communication of data from protected area monitoring and vigilance efforts, which has proven to be a useful tool in many countries globally (Critchlow et al., 2017). Nonetheless, most aspects of the illegal poaching and trade of the globally endangered Baird's tapir remain unknown. It is therefore critical to better understand the current state of tapir poaching and trafficking and to immediately act in contexts where either occur at any level.

\subsection{Work with indigenous communities}

In addition to protected areas, much of the remaining habitat for Baird's tapir also occurs in indigenous areas, where indigenous communities often are more effective at conserving wildlife habitat than State government agencies (Bray et al., 2008; Porter-Bolland et al., 2012). A recent map of Central America produced by the IUCN showed that indigenous people's territories coincide with more than half of the region's remaining forests. This, along with recent initiatives to promote Indigenous and Community Conserved Areas (ICCAs), have sought to more formally and consistently recognize the role of indigenous people as guardians of the region's last intact forested areas. Indigenous people are possibly the most important allies that conservationists have in protecting habitat for endangered species (Schwartzman et al., 2000). They may have deep, even spiritual, ties to species such as the tapir. In community conserved areas, agreements with local/indigenous communities that help mitigate threats, including unsustainable levels of deforestation and over-hunting, are essential. An example of this includes the signing of a regional agreement on non-hunting of tapir within lands managed by local communities in México, such as within the protected natural areas of the Sierra Madre de Chiapas (de la Torre et al., 2017).

In some high priority patches, State governments have also granted legal tenure and certain levels of legal autonomy to indigenous communities, including in the Honduran Moskitia where 11 indigenous territories were granted titles to approximately 1.4 million hectares in 2016 and the 23 indigenous territories that cover nearly the entirety of Nicaragua's Caribbean Coast. However, despite legal recognition of their rights to their ancestral lands, these communities are often under pressure from illegal colonists driving cattle ranching and agricultural frontiers, lack adequate support from State governments, and lack the necessary resources to monitor and enforce their land rights (Stocks et al., 2007). Thus, strategies that would enhance funds, staff, technology, and training for indigenous territories will be crucial to protecting these areas. In many cases, protected areas and indigenous communities overlap. In this case, some suggest that management responsibilities should be passed from federal institutions to local communities (Bonham et al., 2008). All strategies implemented in indigenous territories must abide by international instruments designed to protect the traditions, cultures, languages, and self-determination of indigenous peoples (i.e. ILO Convention 169). Despite these recommendations, there is no blanket solution for cases involving conservation and indigenous or local communities. It is critically important to consider the specific social context of each situation before implementing any of these strategies.

Payments for Ecosystem Services (PES) can also be used as a strategy to help maintain existing habitat and to fund indigenous and local peoples' conservation efforts. We recommend payments specifically placed in communities that maintain tapir habitat or critical areas for connectivity, with a specific spatial focus on the outlined habitat patches represented in the network connectivity model. PES has successfully been used to provide economic compensation to local communities that protect critical habitat or important areas for the connectivity (de la Torre et al., 2018). Through this economic incentive, local communities can be encouraged to protect forested lands and to conduct activities compatible with forest conservation. For example, communities can promote eco-tourism with the Baird's tapir as their flagship species to increase opportunities for community engagement and long-term economic commitment to forest restoration beyond initial PES. Additionally, in areas with high deforestation, we recommend PES as a means of aiding in reforestation, with a specific focus on reforestation within flow nodes and areas surrounding habitat patches presented in the network connectivity model.

\subsection{Re-establish and strengthen connectivity}

Areas with poor connectivity include southwestern Mexico and Honduras, where the distance between patches is too far, as well as areas with major dispersal barriers (e.g. Panama Canal). Strategies to promote connectivity could include the purchase of private land to preserve or restore habitat that can act as stepping stones for the species dispersing between the larger patches (Worboys et al., 2010). Another strategy is to work with large agricultural or forestry operations to facilitate movement corridors (Meijaard et al., 2005). In order to plan for both of these actions, detailed information on land ownership and concessions is still necessary (Miller et al., 2001).

The path of the proposed Nicaragua Canal could create another disruption in connectivity for the species and destroy a large portion of an important habitat patch (ID 19). Some strategies have been suggested to reduce the impact of this canal (Jordan et al., 2016). Even if such strategies were employed, the development associated with the canal would present a major barrier to dispersal, as evidence suggests the Panama Canal already does for tapir (Meyer et al., 2015; Meyer et al., 2013; Moreno, 1993). Major roads also act as dispersal barriers for large mammals like the tapir, with potential negative genetic effects and influences on overall species health (Holderegger and Di Giulio, 2010). To improve the connectivity across the species range, it is necessary that major roads that interrupt the connectivity for Baird's tapir populations include mitigation measures to avoid wildlife collisions. Some projects have focused specifically on tapir-mortality when dispersing across roads (e.g. The Belize Tapir Project, Lowland Tapir Conservation Initiative in South America, Nai Conservation in Costa Rica). Wildlife under- and overpasses, installation of road signs and speed bumps, and reflective collars on individuals are all potential strategies to promote connectivity (by preventing wildlife collisions) for tapir populations that require further investigation in Central America. However, even the best mitigation efforts will not overcome massive road development, meaning that conservationists must be engaged with development plans at the local level to discourage road construction in highly vulnerable or important tapir patches (Glista et al., 2009).

\subsection{Conduct additional surveys}

Fourteen of the habitat patches identified in our analysis have no confirmed tapir presence, and have experienced very few, if any, survey efforts. Most of these patches are small (mean estimated population size $=27, \max =82$ ), and several of them are very close to larger patches, suggesting they are not stronghold populations. However, additional surveys in some small patches should be prioritized due to their location in highly fragmented landscapes where maintaining connectivity is critical. In some cases, these patches may acquire additional importance under future habitat or climate change.

First, there are several small patches throughout Honduras that 
should be prioritized. Although species data exist in some of these patches, this area is so crucial to the connectivity due to its central location in the network that all of these patches could represent important stepping stones. There also are several nearby smaller patches ( $<10$ individuals) and protected areas that could serve this purpose, and that have confirmed tapir presence, including La Muralla Wildlife Refuge and Cusuco National Park (McCann et al., 2012; SagastumeEspinoza and Romero, 2017). A similar area of high fragmentation and low connectivity can be found in Southern México, between Selva Zoque (ID 4 \& 5), the Sierra Madre de Chiapas (SMC) (ID 7), and Selva Lacandona (ID $6 \&$ 9). The estimated low connectivity in this area is partially due to the inability of the model to predict a substantial population in the SMC, which experts have estimated as harboring 225 tapirs across $1500 \mathrm{~km}^{2}$ of habitat (Naranjo, 2009). However, a recent study that investigated the connectivity of this area, and included the SMC as occupied habitat patches, still found limited connectivity in this region, and a high level of threat in close proximity to these important habitat patches (de la Torre et al., 2018; Godínez-Gómez et al., in press).

In addition to surveys to confirm presence in important patches, the distribution model would benefit from surveys conducted in habitats that are underrepresented in the species data. Most of the available species data is from the fringe of habitat patches. There are few surveys from low suitability areas, because researchers targeting tapir or other endangered species often want to ensure they have some detections. On the other hand, there are also few surveys from deep within habitat cores, likely due to problems with accessibility. Targeting future surveys in these two types of habitats, would likely improve model accuracy and precision and further inform conservation actions.

\subsection{Collect additional telemetry and genetic data}

This research was based on limited knowledge about the individual movements of Baird's tapir. Small changes in home range size and long distance dispersal could have a significant impact on the results. Estimates of home range size for the species range from 1 to $24 \mathrm{~km}^{2}$, though these are based on very small sample sizes (i.e. 1-5 individuals) and simple methods (Foerster and Vaughan, 2002; Reyna-Hurtado et al., 2016). Changes to the home range estimates would impact estimates of species density through our assumption about the area sampled around each camera station (i.e. the Effective Sample Area, or ESA), because the ISDM requires knowledge of this property as an input to the model. Any resulting changes to species density would have corresponding effects on the patches that are included in the analyses. Additional data on tapir movements would also improve the connectivity model, and thus provide greater accuracy in estimating the flow between patches, and identifying where any breaks in the network of patches may occur.

The collection of genetic data would also be immensely beneficial to this research, in that it could be used to help train or validate connectivity models (Manel and Holderegger, 2013), as well as used to identify individuals as inputs for spatial capture-recapture (SCR) models, which would provide more robust estimates of species density (Royle et al., 2013). However, the collection of these data can be costly. Some researchers are collecting genetic data from roadkills, which reduces the costs of finding and capturing individuals (e.g. Lowland Tapir Initiative in Brazil with Tapirus terrestris, and Nai Conservation in Costa Rica with Tapirus bairdii). Another lower-cost alternative is to collect these data through scat or hair traps (Fuller et al., 2016; Lamb et al., 2018). These genetic samples will further provide information about connectivity through meta-population and genetic admixture analyses, estimate inbreeding depression, and further inform population viability models. The Baird's Tapir Survival Alliance and other partners have recently begun collecting these and other much needed natural history data on Baird's tapirs to better inform all future distribution, population, and connectivity models. With our first examination of population clustering and connectivity, we provide the insights necessary to predict areas for those future surveys and provide a framework for other researchers to integrate these approaches in the conservation planning for other endangered and threatened species across their global distributions.

\section{CRediT authorship contribution statement}

Cody J. Schank: Conceptualization, Methodology, Software, Validation, Formal analysis, Data curation, Writing - original draft, Writing - review \& editing, Visualization. Michael V. Cove: Data curation, Writing - review \& editing. Eugenio Y. Arima: Data curation, Writing - review \& editing. Laroy S.E. Brandt: Data curation, Writing review \& editing. Esteban Brenes-Mora: Data curation, Writing - review \& editing. Andrew Carver: Data curation, Writing - review \& editing. Angelica Diaz-Pulido: Data curation, Writing - review \& editing. Nereyda Estrada: Data curation, Writing - review \& editing. Rebecca J. Foster: Data curation, Writing - review \& editing. Oscar Godínez-Gómez: Data curation, Writing - review \& editing. Bart $\mathbf{J}$. Harmsen: Data curation, Writing - review \& editing. Christopher A. Jordan: Data curation, Writing - review \& editing. Timothy H. Keitt: Data curation, Writing - review \& editing. Marcella J. Kelly: Data curation, Writing - review \& editing. Joel Sáenz Méndez: Data curation, Writing - review \& editing. Eduardo Mendoza: Data curation, Writing - review \& editing. Ninon Meyer: Data curation, Writing - review \& editing. Gilberto Pozo Montuy: Data curation, Writing - review \& editing. Eduardo J. Naranjo: Data curation, Writing - review \& editing. Clayton K. Nielsen: Data curation, Writing - review \& editing. Georgina O'Farrill: Data curation, Writing - review \& editing. Rafael Reyna-Hurtado: Data curation, Writing - review \& editing. Marina Rivero: Data curation, Writing - review \& editing. José Pablo Carvajal Sánchez: Data curation, Writing - review \& editing. Maggie Singleton: Data curation, Writing - review \& editing. J. Antonio de la Torre: Data curation, Writing - review \& editing. Margot A. Wood: Data curation, Writing - review \& editing. Kenneth R. Young: Data curation, Writing review \& editing. Jennifer A. Miller: Data curation, Writing - review \& editing.

\section{Acknowledgements}

Armando J. Dans, Carolina Sáenz-Bolaños, Celso Poot, Diego J. Lizcano, Eduardo Carrillo Jimenez, Francisco Botello, Jess Fort, Manolo García Vettorazzi, Manuel Spínola, Niall McCann, Raquel Leonardo, Ricardo Moreno, Sebastian Mejia, and Victor Montalvo for providing data. Funding for Cody Schank during the research and writing of this manuscript was provided by the Donald D. Harrington Fellowship through the Graduate School at the University of Texas at Austin. G.P.M: National Commission of Protected Natural Areas of Mexico and Biosphere Reserve Selva El Ocote Direction by the PROCER program 2014-2016. RR-H: El Colegio de la Frontera Sur in Mexico provided time and money to collect some data. NM and RM: Funding from MWH, Ministerio de Ambiente de Panamá, GEMAS/Fondo Darien, Fundacion Natura. JF: Funding from PANTHERA; with additional support from the McIntire-Stennis Cooperative Forestry Research Program, Department of Forestry and Cooperative Wildlife Research Laboratory at Southern Illinois University. Permits from Ministerio de Ambiente de Panamá. Logistical support from PeaceCorps - Panamá and Azuero Earth Project. EBM: Zoological Society of London and American Society of Mammalogists for providing funding. Sistema Nacional de Áreas de Conservación of Costa Rica for logistical support. JAT and MR: Conservation Program of Endangered Species (PROCER-Mexico) of the National Commission of Protected Areas (CONANP-Mexico), and the Natural Resources Protection Area La Frailescana. 


\section{Declaration of competing interest}

There are no conflicts of interest.

\section{Appendix A. Supplementary data}

Supplementary data to this article can be found online at https:// doi.org/10.1016/j.biocon.2020.108501.

\section{References}

Albert, C.H., Rayfield, B., Dumitru, M., Gonzalez, A., 2017. Applying network theory to prioritize multispecies habitat networks that are robust to climate and land-use change. Conservation Biology: The Journal of the Society for Conservation Biology 31 (6), 1383-1396.

Altrichter, M., Taber, A., Beck, H., Reyna-Hurtado, R., Lizarraga, L., Keuroghlian, A., Sanderson, E.W., 2012. Range-wide declines of a key Neotropical ecosystem architect, the near threatened white-lipped peccary Tayassu pecari. Oryx 46 (1), 87-98.

Arino, O., Perez, J. J. R., Kalogirou, V., Bontemps, S., Defourny, P., \& Van Bogaert, E. (2012). Global land cover map for 2009 (GlobCover 2009). doi:https://doi.pangaea. de/10.1594/PANGAEA.787668.

Balmford, A., Whitten, T., 2003. Who should pay for tropical conservation, and how could the costs be met? Oryx 37 (2), 238-250.

Bélisle, M., 2005. Measuring landscape connectivity: the challenge of behavioral landscape ecology. Ecology 86 (8), 1988-1995.

Bello, C., Galetti, M., Pizo, M.A., Magnago, L.F.S., Rocha, M.F., Lima, R.A.F., Jordano, P., 2015. Defaunation affects carbon storage in tropical forests. Sci. Adv. 1 (11), e1501105.

Benítez-López, A., Santini, L., Schipper, A.M., Busana, M., Huijbregts, M.A.J., 2019. Intact but empty forests? Patterns of hunting-induced mammal defaunation in the tropics. PLoS Biol. 17 (5), e3000247.

Bonham, C.A., Sacayon, E., Tzi, E., 2008. Protecting imperiled "paper parks": potential lessons from the Sierra Chinajá, Guatemala. Biodivers. Conserv. 17 (7), 1581-1593.

Bowman, J., Jaeger, J.A.G., Fahrig, L., 2002. Dispersal distance of mammals is proportional to home range size. Ecology 83 (7), 2049-2055.

Bray, D.B., Duran, E., Ramos, V.H., Mas, J.-F., Velazquez, A., McNab, R.B., Radachowsky, J., 2008. Tropical deforestation, community forests, and protected areas in the Maya Forest. Ecol. Soc. 13 (2).

Brooks, D.M., Bodmer, R.E., Matola, S., 1997. Tapir Action Plan. IUCN/SSC Tapir Specialist Group.

Bruner, A.G., Gullison, R.E., Balmford, A., 2004. Financial costs and shortfalls of managing and expanding protected-area systems in developing countries. Bioscience 54 (12), 1119-1126.

Brunn, S.D., 2011. Engineering Earth: The Impacts of Megaengineering Projects. Springer Science \& Business Media.

Cove, M.V., Pardo Vargas, L.E., de la Cruz, J.C., Spínola, R.M., Jackson, V.L., Saénz, J.C., Chassot, O., 2014. Factors influencing the occurrence of the endangered Baird's tapir Tapirus bairdii: potential flagship species for a Costa Rican biological corridor. Oryx 48 (3), 402-409.

Critchlow, R., Plumptre, A.J., Alidria, B., Nsubuga, M., Driciru, M., Rwetsiba, A., Beale, C.M., 2017. Improving law-enforcement effectiveness and efficiency in protected areas using ranger-collected monitoring data. Conserv. Lett. 10 (5), 572-580.

Csardi, G., Nepusz, T., 2006. The igraph software package for complex network research. InterJournal, Complex Systems 1695 (5), 1-9.

Dilts, T.E., Weisberg, P.J., Leitner, P., Matocq, M.D., Inman, R.D., Nussear, K.E., Esque, T.C., 2016. Multiscale connectivity and graph theory highlight critical areas for conservation under climate change. Ecol. Appl. 26 (4), 1223-1237.

Dirzo, R., Young, H.S., Galetti, M., Ceballos, G., Isaac, N.J.B., Collen, B., 2014 Defaunation in the anthropocene. Science 345 (6195), 401-406.

Dorazio, R.M., 2014. Accounting for imperfect detection and survey bias in statistical analysis of presence-only data. Global Ecology and Biogeography: A Journal of Macroecology 23 (12), 1472-1484.

Elliot, N.B., Cushman, S.A., Macdonald, D.W., Loveridge, A.J., 2014. The devil is in the dispersers: predictions of landscape connectivity change with demography. The Journal of Applied Ecology 51 (5), 1169-1178.

Estrada, E., Bodin, O., 2008. Using network centrality measures to manage landscape connectivity. Ecol. Appl. 18 (7), 1810-1825.

Etherington, T.R., 2016. Least-cost Modelling and landscape ecology: concepts, applications, and opportunities. Current Landscape Ecology Reports 1 (1), 40-53.

van Etten, J., 2017. R package gdistance: distances and routes on geographical grids. J. Stat. Softw. 76 (13), 1-21.

Eugster, M.J.A., Schlesinger, T., 2010. Osmar: OpenStreetMap and R. (R Journal).

Ferreguetti, Á.C., Tomás, W.M., Bergallo, H.G., 2017. Density, occupancy, and detectability of lowland tapirs, Tapirus terrestris, in Vale Natural Reserve, southeastern Brazil. J. Mammal. 98 (1), 114-123.

Foerster, C.R., Vaughan, C., 2002. Home range, habitat use, and activity of Baird's Tapir in Costa Rica. Biotropica 34 (4), 423-437.

Foltete, J.-C., Clauzel, C., Vuidel, G., Tournant, P., 2012. Integrating graph-based connectivity metrics into species distribution models. Landsc. Ecol. 27, 557-569.

Fragoso, J. (1983). The ecology and behavior of Baird's tapir in Belize. Documento del centro de Documentación de la Universidad de Heredia, Costa Rica.

Frankham, R., 2005. Genetics and extinction. Biol. Conserv. 126 (2), 131-140.
Franklin, J., 2010. Mapping Species Distributions: Spatial Inference and Prediction. Cambridge University Press.

Fuller, A.K., Sutherland, C.S., Royle, J.A., Hare, M.P., 2016. Estimating population density and connectivity of American mink using spatial capture-recapture. Ecol. Appl. 26 (4), 1125-1135.

García, M., Jordan, C.A., O’Farril, G., Poot, C., Meyer, N., Estrada, N., Ruiz-Galeano, M., 2016. Tapirus bairdii. https://doi.org/10.2305/IUCN.UK.2016-1.RLTS T21471A45173340.en.

Gastón, A., Blázquez-Cabrera, S., Garrote, G., Mateo-Sánchez, M.C., Beier, P., Simón, M.A., Saura, S., 2016. Response to agriculture by a woodland species depends on cover type and behavioural state: insights from resident and dispersing Iberian lynx. The Journal of Applied Ecology 53 (3), 814-824.

Getis, A., Ord, J.K., 1992. The Analysis of Spatial Association by Use of Distance Statistics. Geogr. Anal. 24 (3), 189-206.

Girot, P.O., 2002. The Darien Region Between Colombia and Panama: Gap or Seal? Human Rights and the Environment: Conflicts and Norms in a Globalizing World. 174.

Glista, D.J., DeVault, T.L., DeWoody, J.A., 2009. A review of mitigation measures for reducing wildlife mortality on roadways. Landsc. Urban Plan. 91 (1), 1-7.

Godínez-Gómez, O., Naranjo, E. J., Bermúdez, D. W., Pozo-Montuy, G., Schank, C. J., \& Mendoza, E. 2020 (in press). An analysis of the connectivity of the habitat remnants of the Central American tapir (Tapirus bairdii) in southeastern Mexico. Journal for Nature Conservation.

Google Earth Engine Team, 2015. Google Earth Engine: A planetary-scale geo-spatial analysis platform [Data set]. Retrieved from. https://earthengine.google.com.

Grajales, J., 2013. State involvement, land grabbing and counter-insurgency in Colombia. Dev. Chang. 44 (2), 211-232.

Hansen, M.C., Potapov, P.V., Moore, R., Hancher, M., Turubanova, S.A., Tyukavina, A., Townshend, J.R.G., 2013. High-resolution global maps of 21st-century forest cover change. Science 342 (6160), 850-853.

Hijmans, R. J., van Etten, J., Cheng, J., Mattiuzzi, M., Sumner, M., Greenberg, J. A., .. Others. (2016). Package "raster." R Package. Https://cran. R-Project. Org/web/ packages/raster/index. Html (accessed 1 October 2016).

Holderegger, R., Di Giulio, M., 2010. The genetic effects of roads: a review of empirical evidence. Basic and Applied Ecology 11 (6), 522-531.

Huete, A. R., HuiQing Liu, \& van Leeuwen, W. J. D. (1997). The use of vegetation indices in forested regions: issues of linearity and saturation. IGARSS'97. 1997 IEEE International Geoscience and Remote Sensing Symposium Proceedings. Remote Sensing - a Scientific Vision for Sustainable Development, vol. 4, 1966-1968 vol.4. ieexplore.ieee.org.

Isaac, N.J.B., Turvey, S.T., Collen, B., Waterman, C., Baillie, J.E.M., 2007. Mammals on the EDGE: conservation priorities based on threat and phylogeny. PLoS One 2 (3), e296.

IUCN, 2019. The IUCN red list of threatened species. Version 2019-3. http://www. iucnredlist.org.

IUCN-ORMACC, 2016. Map of the Indigenous Peoples, Protected Areas and Natural Ecosystem of Central America. (Data set).

Joppa, L.N., Loarie, S.R., Pimm, S.L., 2008. On the protection of "protected areas.". Proc. Natl. Acad. Sci. 105 (18), 6673-6678.

Jordan, C.A., Galeano, M.R., Alonzo, A.S., 2014. La Cacería Historica de Tapires Centroamericanos (Tapirus bairdii) en la RAAS. Nicaragua. Estud Ambient 1 (1), 73-87.

Jordan, C.A., Schank, C.J., Urquhart, G.R., Dans, A.J., 2016. Terrestrial mammal occupancy in the context of widespread Forest loss and a proposed interoceanic canal in Nicaragua's decreasingly remote South Caribbean region. PLoS One 11 (3), e0151372.

Jordan, C.A.J., Hoover, B., Dans, A.J., Schank, C., Miller, J.A., 2019. The impact of hurricane Otto on Baird's Tapir Movement in Nicaragua's Indio Maíz Biological Reserve. In: Reyna-Hurtado, R., Chapman, C.A. (Eds.), Movement Ecology of Neotropical Forest Mammals. Springer, pp. 5-20.

Karger, D.N., Conrad, O., Böhner, J., Kawohl, T., Kreft, H., Soria-Auza, R.W., Kessler, M. 2017. Climatologies at high resolution for the earth's land surface areas. Scientific Data 4, 170122.

Keeley, A.T.H., Beier, P., Keeley, B.W., Fagan, M.E., 2017. Habitat suitability is a poor proxy for landscape connectivity during dispersal and mating movements. Landsc. Urban Plan. 161, 90-102.

Koshkina, V., Wang, Y., Gordon, A., Dorazio, R.M., White, M., Stone, L., 2017. Integrated species distribution models: combining presence-background data and site-occupancy data with imperfect detection. Methods Ecol. Evol. 8 (4), 420-430.

Lamb, C.T., Mowat, G., Reid, A., Smit, L., Proctor, M., McLellan, B.N., Boutin, S., 2018. Effects of habitat quality and access management on the density of a recovering grizzly bear population. The Journal of Applied Ecology 55 (3), 1406-1417.

MacKenzie, D.I., Nichols, J.D., Lachman, G.B., Droege, S., Royle, J.A., Langtimm, C.A., 2002. Estimating site occupancy rates when detection probabilities are less than one. Ecology 83 (8), 2248-2255.

MacKenzie, D.I., Nichols, J.D., Hines, J.E., Knutson, M.G., Franklin, A.B., 2003. Estimating site occupancy, colonization, and local extinction when a species is detected imperfectly. Ecology 84 (8), 2200-2207.

Manel, S., Holderegger, R., 2013. Ten years of landscape genetics. Trends Ecol. Evol. 28 (10), 614-621.

McCann, N.P., Wheeler, P.M., Coles, T., Bruford, M.W., 2012. Rapid ongoing decline of Baird's tapir in Cusuco National Park, Honduras. Integrative Zoology 7, 420-428.

Medici, E.P., Desbiez, A., 2012. Population viability analysis: using a modeling tool to assess the viability of tapir populations in fragmented landscapes. Integrative Zoology 7 (4), 356-372.

Medici, E.P., Carrillo, L., Montenegro, O.L., Miller, P.S., Carbonell, F., Chassot, O. Mendoza, A., 2005. Baird's tapir (Tapirus bairdii) conservation workshop population 
and habitat viability assessment (PHVA). IUCN/SSC Tapir Specialist Group 1-180.

Meijaard, E., Sheil, D., Nasi, R., Augeri, D., Rosenbaum, B., Iskandar, D., O’Brien, T. 2005. Life After Logging: Reconciling Wildlife Conservation and Production Forestry in Indonesian Borneo. CIFOR.

Mendoza, E., Fuller, T.L., Thomassen, H.A., Buermann, W., Ramírez-Mejía, D., Smith, T.B., 2013. A preliminary assessment of the effectiveness of the Mesoamerican Biological Corridor for protecting potential Baird's tapir (Tapirus bairdii) habitat in southern Mexico. Integrative Zoology 8 (1), 35-47.

Meyer, N., Moreno, R., Jansen, P.A., 2013. Distribution and conservation status of the Baird's tapir in Panama. Tapir Conservation 22 (30), 10-13.

Meyer, N., Esser, H.J., Moreno, R., van Langevelde, F., Liefting, Y., Ros Oller, D., Jansen, P.A., 2015. An assessment of the terrestrial mammal communities in forests of Central Panama, using camera-trap surveys. J. Nat. Conserv. 26, 28-35.

Miller, K., Chang, E., Johnson, N., 2001. Defining Common Ground for the Mesoamerican Biological Corridor. World Resources Institute, Washington, DC.

Moreno, S.H., 1993. Impact of development on the Panama canal environment. Journal of Interamerican Studies and World Affairs 35 (3), 129-149.

Naranjo, E.J., 2009. Ecology and conservation of Baird's tapir in Mexico. Mongabay.com Open Access Journal - Tropical Conservation Science 2 (2), 140-158.

Naranjo, E.J., 2018. Baird's tapir ecology and conservation in Mexico revisited. Tropical Conservation Science 11, 1940082918795558.

Naranjo, E.J., Alcalá, S.A.A., Briones, F.A.F., Hurtado, R.A.R.-H., 2015. Distribución, abundancia y amenazas a las poblaciones de tapir (Tapirus bairdii) y pecarí de labios blancos (Tayassu pecari) en México. THERYA 6 (1), 227-249.

NASA, 2017. MODIS Collection 6 NRT Hotspot/Active Fire Detections MCD14DL [Data set]. https://doi.org/10.5067/FIRMS/MODIS/MCD14DL.NRT.006.

Nathan, R., Klein, E., Robledo-Arnuncio, J.J., Revilla, E., 2012. Dispersal Kernels: Review. Dispersal Ecology and Evolution. Oxford University Press, Oxford, pp. 187-210.

O'Farrill, G., Calmé, S., Sengupta, R., Gonzalez, A., 2012. Effective dispersal of large seeds by Baird's tapir: a large-scale field experiment. J. Trop. Ecol. 28 (1), 119-122.

Osuri, A.M., Ratnam, J., Varma, V., Alvarez-Loayza, P., Hurtado Astaiza, J., Bradford, M., Sankaran, M., 2016. Contrasting effects of defaunation on aboveground carbon storage across the global tropics. Nat. Commun. 7, 11351.

Pacifici, K., Reich, B.J., Miller, D.A.W., Gardner, B., Stauffer, G., Singh, S., Collazo, J.A., 2017. Integrating multiple data sources in species distribution modeling: a framework for data fusion. Ecology 98 (3), 840-850.

Pardini, R., Bueno, A. de A., Gardner, T.A., Prado, P.I., Metzger, J.P., 2010. Beyond the fragmentation threshold hypothesis: regime shifts in biodiversity across fragmented landscapes. PLoS One 5 (10), e13666.

Pekel, J.-F., Cottam, A., Gorelick, N., Belward, A.S., 2016. High-resolution mapping of global surface water and its long-term changes. Nature 540 (7633), 418-422.

Peres, C.A., Barlow, J., Laurance, W.F., 2006. Detecting anthropogenic disturbance in tropical forests. Trends Ecol. Evol. 21 (5), 227-229.

Porter-Bolland, L., Ellis, E.A., Guariguata, M.R., Ruiz-Mallén, I., Negrete-Yankelevich, S., Reyes-García, V., 2012. Community managed forests and forest protected areas: an assessment of their conservation effectiveness across the tropics. For. Ecol. Manag. 268, 6-17.

Rabinowitz, A., Zeller, K.A., 2010. A range-wide model of landscape connectivity and conservation for the jaguar, Panthera onca. Biol. Conserv. 143 (4), 939-945.

Reed, D.H., 2004. Extinction risk in fragmented habitats. In: Animal Conservation Forum, 7, 181-191. Press, Cambridge University.

Reyna-Hurtado, R., Sanvicente-López, M., Pérez-Flores, J., Carrillo-Reyna, N., Calmé, S., 2016. Insights into the multiannual home range of a Baird's tapir (Tapirus bairdii) in the Maya Forest. THERYA 7 (2), 271-276.

Ripple, W.J., Newsome, T.M., Wolf, C., Dirzo, R., Everatt, K.T., Galetti, M., Van Valkenburgh, B., 2015. Collapse of the world's largest herbivores. Sci. Adv. 1 (4), e1400103.

Royle, J.A., Chandler, R.B., Sollmann, R., Gardner, B., 2013. Spatial Capture-Recapture Elsevier Science.

Sagastume-Espinoza, K.O., Romero, S.J., 2017. First photographic evidence of the iconic big mammals of Honduras, Baird's tapir (Tapirus bairdii) and jaguar (Panthera onca), in La Muralla wildlife refuge. Therya 8 (1).

Salazar, M., 2018, January. 17. Denuncian a Marena por obstaculizar investigación en Indio Maíz, Confidencial.

Sanderson, E.W., Redford, K.H., Chetkiewicz, C.-L.B., Medellin, R.A., Rabinowitz, A.R., Robinson, J.G., Taber, A.B., 2002. Planning to save a species: the jaguar as a model. Conserv. Biol. 16 (1), 58-72.

Schank, C. J., Mendoza, E., Vettorazzi, M. J. G., Cove, M. V., Jordan, C. A., O'Farrill, G., .. Others. (2015). Integrating current range-wide occurrence data with species distribution models to map the potential distribution of Baird's tapir. Tapir Conservation, 24(33), 15-25.

Schank, C.J., Cove, M.V., Kelly, M.J., Mendoza, E., O'Farrill, G., Reyna-Hurtado, R., Miller, J.A., 2017. Using a novel model approach to assess the distribution and conservation status of the endangered Baird's tapir. Divers. Distrib. 1-13.

Schank, C.J., Cove, M.V., Kelly, M.J., Nielsen, C.K., O’Farrill, G., Meyer, N., Others, ...., 2019. A sensitivity analysis of the application of integrated species distribution models to mobile species: a case study with the endangered Baird's tapir. Environ. Conserv. 46 (3), 184-192.

Schipper, J., Chanson, J.S., Chiozza, F., Cox, N.A., Hoffmann, M., Katariya, V., Young, B.E., 2008. The status of the world's land and marine mammals: diversity, threat, and knowledge. Science 322 (5899), 225-230.

Schwartzman, S., Nepstad, D., Moreira, A., 2000. Arguing tropical forest conservation: people versus parks. Conservation Biology: The Journal of the Society for Conservation Biology 14 (5), 1370-1374.

Schwerdtfeger, W., 1976. World Survey of Climatology Volume 12: Climates of Central and South America. Elsevier Scientific Publishing Company Amsterdam.

Stocks, A., McMahan, B., Taber, P., 2007. Indigenous, colonist, and government impacts on Nicaragua's Bosawas Reserve. Conserv. Biol. 21 (6), 1495-1505.

de la Torre, J.A., Núñez, J.M., Medellín, R.A., 2017. Habitat availability and connectivity for jaguars (Panthera onca) in the Southern Mayan Forest: Conservation priorities for a fragmented landscape. Biol. Conserv. 206, 270-282.

de la Torre, J.A., Rivero, M., Camacho, G., Álvarez-Márquez, L.A., 2018. Assessing Occupancy and Habitat Connectivity for Baird's Tapir to Establish Conservation Priorities in the Sierra Madre de Chiapas. (Mexico. Journal for Nature Conservation).

Tyre, A.J., Tenhumberg, B., Field, S.A., Niejalke, D., Parris, K., Possingham, H.P., 2003. Improving precision and reducing bias in biological surveys: estimating false-negative error rates. Ecol. Appl. 13 (6), 1790-1801.

UNEP-WCMC, 2014. The World Database on Protected Areas [Data set]. Retrieved from protectedplanet.net.

Watsa, M.E., 2014, August 13. "Natural Reserves" No More: Illegal Colonists Deforest Huge Portions of Nicaraguan Protected Areas. (Mongabay).

Worboys, G., Francis, W.L., Lockwood, M., 2010. Connectivity Conservation Management: A Global Guide (with Particular Reference to Mountain Connectivity Conservation). Earthscan.

Wultsch, C., Caragiulo, A., Dias-Freedman, I., Quigley, H., Rabinowitz, S., Amato, G., 2016. Genetic diversity and population structure of Mesoamerican jaguars (Panthera onca): implications for conservation and management. PLoS One 11 (10), e0162377.

Zeller, K.A., Rabinowitz, A., 2011. Using Geographic Information Systems for Range-wide Species Conservation Planning. Geographic Information Systems. Nova Science Publishers, Inc., Hauppauge, NY.

Zeller, K.A., McGarigal, K., Whiteley, A.R., 2012. Estimating landscape resistance to movement: a review. Landsc. Ecol. 27 (6), 777-797. 